\title{
DIFFUSION OF INNOVATIONS AS A KEY DRIVER OF THE DIGITAL ECONOMY DEVELOPMENT
}

\author{
Maxim Polyakov' ${ }^{1}$ Nataliia Kovshun ${ }^{2}$
}

\begin{abstract}
The research objective includes detailing of the essence and structural changes of the digital economy (DE) at the national level; an explanation of the features of digital innovations; the role substantiation of diffusion of innovations (DI) as a key driver for DE development. The research methodology is based on: structural, institutional, historical, comparative, functional analysis, formalization method. The need to achieve all-encompassing digitalization nature and the systematic use of digital technologies, as well as the transition to digital models of organization through the diffusion of technologies, is taken into account. The research results are the detailing of the essence and structural features of DE. DE is considered as a new type of economy, characterized by the widespread adoption of digital technologies, cyber-physical systems, intelligent solutions, network technologies. The DE nature is revealed from the position of several approaches: technological; structural; component-resource; functional. The DE features (network nature, a new type of entrepreneurship, a new class of specialists, new institutions, etc.) are highlighted, as well as the negative consequences of the transition to such an economy; overcoming of these negative consequences requires smart policy with a focus on productivity growth, structural changes and growth incentives. The DE structure, including parts of the Internet economy (e-Commerce, e-Health, e-Education, e-Banking, etc.) and new forms of providing various services, is characterized. The IT sector growth is indicated as the DE "core", where new jobs, infrastructure, cost are created, and the technology business is developed. The structural proportions of DE are largely determined by technological trends (on-demand economy, sharing economy, Internet of Things, etc.). Digital platforms as new intermediary mechanisms, as well as the Big Data market, are one of the key structural components of DE. The subject and features of digital innovations are highlighted. On this basis, the DI role in the DE development is substantiated, taking into account the provision of all-encompassing digitalization nature, stimulation of innovations, ensuring the benefits and economic growth, as well as the creation of economies of scale, chain and cumulative effects. Practical recommendations on the intensification of DI processes in the context of DE building include: targeted government support that concerns the IT and other sectors; establishment of technology transfer and commercialization centers, technology platforms and technology leadership programs; quality improvement of education and training; infrastructure role expanding of universities; development of research, innovation, entrepreneurial networks, professional communities, industry associations. In this context, it is necessary to strengthen support for small and medium-sized innovative businesses that should become a provider of new technologies. It is advisable to create portals for oriented R\&D and adoption of technologies; knowledge management platforms during technology transfer process; industry knowledge bases; portals for experts work activity management for project evaluation. Value/originality. The article details the essence and reveals the structural features of $D E$, describes the specifics of digital innovations, as well as presents $\mathrm{DI}$ as a key driver for the development of such an economy.
\end{abstract}

Key words: information technologies, digital economy, digital innovations, diffusion of innovations, digital platforms.

JEL Classification: L86, M15, 014, O32

\footnotetext{
Corresponding author:

${ }^{1}$ National University of Water and Environmental Engineering, Ukraine.

E-mail: polyakovmaxim77@gmail.com

ORCID: https://orcid.org/0000-0001-7896-2486

ResearcherID: V-9971-2018

${ }^{2}$ National University of Water and Environmental Engineering, Ukraine.

E-mail: n.e.kovshun@nuwm.edu.ua

ORCID: https://orcid.org/0000-0003-0573-2932

ResearcherID: K-2688-2018
} 


\section{Introduction}

In recent decades, there has been a rapid progress in computer technologies, the widespread use of information technologies (IT) in various areas of activity, the transfer of various processes of communication, exchange and management to the Internet. All this has modified the economic organization largely and completely. In particular, the so-called information economy and the Internet economy are considered. According to IT development, new generations such as digital technologies have appeared, as well as new information systems such as digital platforms. As a result, intensive digitalization of economic processes and digital transformations of the economic complex began, and it led to the new economy type emergence such as digital economy (DE).

Digital transformations affected trade, provision of various services, government activities (digital government), the social services, including medicine and education. Cyber-physical systems are being created, artificial intelligence is used, new generations of production technologies are emerging (automated robots, software and computer design complexes), the Internet of Things is developing on the basis of digitalization. This became the basis for the formation of new chains of production, supply and consumption that is taking place in the framework of the Fourth Industrial Revolution. This leads to structural changes in the economy, the emergence of new industries and markets, types of services and business, including technology, as well as to the expansion and segmentation of the IT sector.

The full launch of DE and the use of its advantages require comprehensive digital changes in all economy sectors, a high level achievement of their technological convergence, the transition to new models of economic organization, as well as other (non-economic) structures in the life of society. This necessitates the full diffusion and adoption of digital technologies. In this regard, the diffusion of innovations (DI) should be considered as one of the most important key drivers of $\mathrm{DE}$ formation and development.

The objective nature of technological progress requires special attention to DI in order to adapt the economy to new conditions, to overcome structural and social problems, and to obtain general benefits from digital technologies. In this regard, DI concerns not only sectors of the economy, but it also has a spatial aspect, contributing to the development of territories and the division of labor. In addition, DI deals with human and social development, improving the business environment. Considering the above, DI in digitalization has a structural significance and it should be an object of strategic management. The intensification of the diffusion processes of new digital technologies, information services and products, should be driven by state innovation policy and it requires the support.

\section{Literature review}

Discussions about DE began a long time ago, in the middle 1990s. It was closely related to the Internet economy (Choi, Whinston, 2000), the intensification of electronic commerce and social communications, which had great economic consequences, followed by social and organizational changes. The Internet quickly became global (Brynjolfsson, Kahin, 2000). The widespread use of IT made them as a new infrastructure of the economy, which led to the DE identification.

Digital IT became major areas of innovations in the latter half of the 20th century and the beginning of the 21st century. A high focus on innovations has fundamentally changed the traditional ways of doing business, and also created a qualitatively new type of entrepreneurship, making an even greater demand for knowledge, skills and technology. DE formation leads to further IT sector growth, including specialists: programmers, data processing specialists, managers, economists, venture capitalists and investors. This has created a new social class, a large community that ensures the development and diffusion of new IT. On the other hand, the people who widely use IT in life have become more receptive to innovations (Hevner, Gregor, 2020). Many digital innovations are not related only to IT, but also to the service information systems (IS) that provide with the digital services implementation. Also, IS implement new organizational and communication mechanisms. IT and IS together make it possible to create new information products (Iden, Eikebrokk, Marrone, 2020).

The issue of innovations is a cornerstone of $\mathrm{DE}$ understanding. Compared to the industrial economy, value creation seems to be more difficult because of the saturation, "intangibility", and more intense competition. In the digital context, the essence, criteria and features of innovation are changing, in particular, the excess of social profit over private. New institutional problems obviously appear, including those ones related to the intellectual property protection (Teece, 2018).

New digital technologies adaptation is necessary to improve business efficiency and competitiveness (El-Haddadeh, 2020). Despite the fact that large companies dominate in IT and Internet sectors (for example, Facebook, Apple, Amazon, Microsoft, Netflix, and Google), DE development opens up new opportunities for small and medium-sized enterprises, including in small cities and even in rural areas. This is the case of the development of global, regional and local innovations. These can be information services that make it possible to improve competitiveness, accelerate market exchange and knowledge processing. At the same time, it requires appropriate digital competence (Räisänen, Tuovinen, 2020). In a DE context, companies need digital competencies to develop or master innovations in the context of diffusion. This is described by various theories and 
models, for example: Expectancy Disconfirmation Model, Model for Organization Adoption, Model of Personal Computer Utilization, Task-Technology Fit model, Technology Acceptance Model, Innovation Diffusion Theory, Unified Theory of Acceptance and Use of Technology, Value-based Adoption Model, Technology Continuance Theory, Technology Adoption Lifecycle, etc. (Lai, 2017; Taherdoost, 2018). When it comes to the population as a whole, the focus is on readiness to digital technologies using new skills acquisition (Benson, 2019). In this regard, consumer resistance to innovations is also considered, as it is an important reason for the rejection of digital innovations, especially technological innovations (Talwar, Talwar, Kaur, Dhir, 2020). Thereby, there is a delayed (long-term) adoption of digital technologies and products is considered due to the attitude towards them, negative image, user orientations, etc. (Jahanmir, Cavadas, 2018).

In the context of $\mathrm{DE}$ building strategies, the issues of diffusion and adoption of digital innovations (technologies) are considered at the national level related to the economic growth and social progress (Park, Choi, 2019). The diffusion and using of new IT can be seen as a separate source of growth, along with new investments, human capital, knowledge, products and services (value).

The $\mathrm{DE}$ formation is extremely uneven, specifically across countries; it is characterized by digital divides at the individual, organizational, sectoral and macro levels. Any digital divide overcoming is based, in the first turn, on DI, especially technological innovations that are related to other conditions of DE (Bilozubenko, Yatchuk, Serediuk, Korneyev, 2020). DI is closely related to the specifics of innovation processes. First of all, this concerns open innovations that are very common in the IT sector and create market demand (for example, the Internet of Things, Big Data and Artificial Intelligence) (Park, 2017).

In order to understand the $\mathrm{DE}$, it is important to note that it is closely intersected with such a major trend as the Fourth Industrial Revolution or Industry 4.0 (Mubarak, Petraite, 2020), which concerned with the implementation of cyber-physical systems in production and service, covering the domestic sphere. Cyber-physical technologies connect digital and physical worlds, improving work processes and increasing productivity, changing the nature and environment of work (Pereira, Romero, 2017).

Digital technology is an important foundation of Industry 4.0, namely, its constituent processes (robotization, automation) and technologies (Internet of Things, Big Data, Virtual and Augmented Reality, 3D Printing, Quantum Computing, Blockchain, etc.). A complex of different technologies that represent Industry 4.0 forms a new technological architecture of production systems, increases productivity, management quality and creates new value for the consumer, shortens the life cycle of goods and services. Therefore, Industry 4.0 makes conditions for a variety of innovations demand, including digital technologies (IT) for industrial, commercial and consumer use, organizational and marketing innovations, and new products and materials on numerous occasions. Overall, the pace of innovation is accelerating, requiring continual improvement in both business models, which accelerates DI processes.

The DE building has become one of the most important areas of modernization in recent years, especially for developing countries. IT consumption is becoming a development factor, including human development (Njoh, 2018). Digitalization is considered as a powerful factor in economic growth, which has already been confirmed in developed and developing countries (Myovella, Karacuka, Haucap, 2020). At the same time, the scale of positive economic effects of digitalization depends on the development level of countries that largely determines the speed of IT diffusion through network infrastructure, digital skills, public and business demand. This is confirmed by the developed countries experience, for example, the Republic of Korea, although this requires the consideration of a larger historical, cultural, political and social context (Larson, 2017). In this regard, the question of the state policy implementation aimed at the diffusion and widespread adoption of IT is raised. At the same time, a key factor in the digital sector development is innovations.

The DE development caused dramatic changes in entrepreneurship. First of all, it opened up new areas for entrepreneurial activity, in particular innovative, and also led to the emergence of new business models. Business digital transformations have specificity in various economy sectors, however, in general, they continue to form a new business environment, change market conditions and economic exchange mechanisms. New opportunities for activity and innovations are opened up for business. However, this requires the development of digital technologies and adaptation to new conditions, in particular, learning how to operate on the basis of digital platforms. In general, DE requires new business strategies, more susceptibility to innovations and the development of innovative capabilities, taking into account digitalization (Nambisan, Wright, Feldman, 2019).

Digital platforms have led to radical changes in many industries, transformed the business models for delivering many services, enabling faster and better service delivery. Productivity growth has been accompanied by declining costs; it has been considered as disruptive innovation as well as creating new value for the consumer. This stimulates companies to reconsideration of their strategies (Zutshi, Grilo, 
2019). At the same time, the external condition for the implementation of new strategies is special conditions for digitalization. Therefore, business orientation and mode of action critically depend on the quality of digital ecosystems. Ecosystems should support innovations, help accumulate and use data, consolidate communities, provide communication between people, provide tools for Big data processing (Chae, 2019). Therefore, different countries declare the need to create an entire digital ecosystem, including institutions, communication and computing network infrastructure, and access to investment resources. The ecosystem approach makes it possible to achieve the integration quality required for DE (Abuladze, Gigauri, 2017). This implies the technological convergence concerned with DI.

Providing of rapid and inclusive digital transformations undoubtedly requires increased government involvement. An appropriate strategy that changes political approaches in different areas in order to enrich the government role in DE development, is needed (Linkov, Trump, Poinsatte-Jones, Florin, 2018). The state should pay special attention to the network infrastructure and population digital skills improving (Bukht, Heeks, 2018). One of its obligatory areas is DI processes support. It is objectively impossible to formation an integral national digital ecosystem that concerns not only the public sector and the social sphere without the government. The state policy of DE development is of particular importance in developing countries, where business potential is comparatively lower than in developed ones (Foster, Azmeh, 2019). In addition, the government contribution to DE creation should be implemented in the context of business adaptation and creation of new conditions for it; it is also related to the formation of a new technological base on a national scale (Hanna, 2018) where DI is of great importance.

The government should help overcome the new DE challenges concerned with unemployment, rapid structural changes, and social inequality. In the light of the growing speed of digital transformation, governments should invest in education and other programs to realize the benefits of DE (Amuso, Poletti, Montibello, 2019). It is also related to DI, as it defines the education horizons, as well as the implementation of digital changes in the delivery of public services.

In general, DI is a very relevant area of DE research, which is being neglected. Certain works show the research importance of: IT innovation diffusion determinants (Lei, 2016) patterns and models that depend on the characteristics of innovations; DI impact on economic growth (Pradhan, Arvin, Nair, Bennett, Hall, 2019); social aspects and consequences (Ali, Mahdi, 2016).

\section{The research objective}

The research objective includes: 1) detailing the essence and structural changes of the DE at the national level; 2) clarification of the digital innovation features; 3) substantiation of the DI role as a key driver of DE development.

\section{Methodology}

In order to achieve the set research objective it is necessary, in addition to meta-analysis of previous developments in this area, to use of a number of qualitative analysis methods, including: structural, institutional, historical, comparative, functional analysis, as well as formalization method in relation to $\mathrm{DE}$, digital technologies, innovations and DI processes.

Some methodological additions that will be the novelty of this study are required in order to assess the role of DI as a key driver for DE development. DI importance substantiation is based on the fact that it is considered as one of the most critical prerequisites for DE formation and development. This takes into account: 1) the need to achieve an all-encompassing nature of digitalization and the systematic application of digital technologies; 2) a hypothetical mechanism for the transition to digital models of organization due to technology diffusion.

The empirical basis of the research is the experience and achievements of the developed and most successful developing countries of the world in DE building, as well as world indicators of digitalization. The theoretical basis of the DI role research in the DE development, in addition to the main areas of economic theory, is formed by the concepts of innovation systems, the knowledge economy, digital platforms, the Fourth Industrial Revolution, as well as various works of authorship and analytical reports of international organizations on the formation and development of DE.

\section{General explanations}

Essence and structural features of DE. DE is considered as a new type of economy that is characterized by a wide and ubiquitous adoption of digital technologies, cyber-physical systems, intelligent solutions, network and computing technologies. It is not true to completely identify DE with the Internet economy, although they are strongly related, considering the Internet as an infrastructure for communication between people and things. It is necessary to understand that the DE is not a sector, but a new structure-forming basis that changes the mechanisms of functioning, interaction, organization models. The complex nature of $\mathrm{DE}$ requires an explanation of its essence from the position of several approaches, namely: 1) technological approach, that is, taking into account the predominant role of 
digital and web technologies; 2) structural approach, that is, the new component for identification of the economic infrastructure, namely the infrastructure of network communication, data storage and processing; 3 ) component-resource approach, that is, taking into account the importance of data and information resources, material and technical and intellectual resources, including software; 4) functional approach, that is, taking into account new features of the economy functioning, including transactions, exchange operations, market search. Naturally, in the context of these approaches, social factors are also important, including digital skills, adaptation to new organizational models through IT. Besides, it should be taken into account that there is a new technological and virtual-social environment in $\mathrm{DE}$, which is complemented by new formal and informal institutions; it affects DI.

The key features of DE are: network character; multilateral markets; a new type of entrepreneurship; a new type of labor and a class of specialists; new institutions; targeted investment. Due to the technological progress objectivity, the transition to $\mathrm{DE}$ is irreversible, but its consequences are ambiguous. In the short term, problems will appear in the field of personal information protection (personal secret disappearance), the formation of ubiquitous behavior control systems, mass behavior manipulation, deintellectualization, job cuts, inequality level increase, the collapse of traditional models of life, family, business, digital isolation growth and other digital threats. In order to overcome these problems it is necessary to conduct a smart policy of eliminating negatives with a focus on the benefits, such as: productivity growth, the emergence of new industries, stimulation of physical barriers, free communication, knowledge processing. The obvious irreversibility of the DE transition requires the development of measures aimed at the negative consequences compensation, which is also concerned with DI.

Exactly positive forecasts for the Internet development should be taken into account. Thus, a steady growth in the number of the Internet users is expected during 2018-2023 (bln): 2018 - 3.9, 2019 4.2, 2020 - 4.5, 2021 - 4.7, 2022 - 5.0, 2023 - 5.3. The growth in the number of mobile subscribers in the world will have such dynamics (bln subscribers): 2018 - 5.1, 2019 - 5.2, 2020 - 5.3, 2021- 5.5, 2022 $5.6,2023-5.7$. The expected growth in the number of M2M connections will be (bln connections): 2018 - 6.1, 2019 - 7.4, 2020 - 8.9, 2021 - 10.6, 2022 12.5, 2023 - 14.7. Global mobile M2M connections are also forecast to grow (bln connections): 2018 - 1.2, 2019 - 1.6, 2020 - 2.2, 2021 - 2.8, 2022 - 3.5, 2023 - 4.4 (Cisco Annual Internet Report (2018-2023) White Paper, 2020). Growing dynamics confirm the great potential of digital transformation in economic growth that can be estimated at up to $10 \%$ of GDP by 2025 .

Digitalization significantly changes the models of economic organization, structure and mechanisms of the economy. This is accompanied by a reduction in the time and cost of searching for information, and reduces transaction costs. The Internet and digital technologies have created new models of functioning in many areas, including: e-Commerce or e-Trade, e-Procurement, e-Auctions, e-Infrastructures, e-Logistics, e-Agriculture, e-Health, e-Education, e-Banking, e-Insurance. Consequently, new marketing mechanisms are emerging, the provision of legal, tourism, brokerage, financial services, etc., as well as crowdfunding, crowdsourcing, outsourcing, outstaffing are developing. Therefore, the IT sector (digital sector) growth is structurally taking place in $\mathrm{DE}$; it is considered as the "core" of DE. It creates new jobs, infrastructure and value; and technology business develops. Around this, digital platforms are formation and then a wide range of other sectors that use digital infrastructure, networks and services.

The structural proportions of $\mathrm{DE}$ are largely determined by global technological trends (in addition to the Fourth Industrial Revolution) that are: circular economy, on-demand economy, sharing economy, Internet of Things, precision farming, artificial intelligence, blockchain, virtual and augmented reality, sensor networks, etc. The so-called "smart things" (wearable devices, clothes, etc.), "smart home", "smart transport", "smart city", "smart jobs", "smart grid", "smart factories", "smart farms", "smart warehouses", "smart infrastructure" are developing.

One of the key structural components of DE is digital platforms operating on the Internet that define new mechanisms for social relations and market exchange. They are information systems connected to production chains, logistics networks, supply chains, acting as an intermediary based on remoteness, hyper-connectivity, decentralization, absence of transaction costs, as well as add intelligent components. Platforms unite network communities (for example, suppliers and consumers), collect large amounts of data, regulate access to resources and activity, create media for communication, open up new opportunities for individual and joint actions, provide various operations and management procedures.

The rapidly growing Internet traffic and the digitalization of historically accumulated data have opened up opportunities for the new direction - Big Data, which is associated with the use of artificial intelligence. The Big Data market is also a new structural element of $\mathrm{DE}$ and it is growing rapidly (Figure 1). At the same time, Big Data technologies are widely used in various fields: medicine, media, marketing, retail, energy, construction, mechanical engineering, etc. 


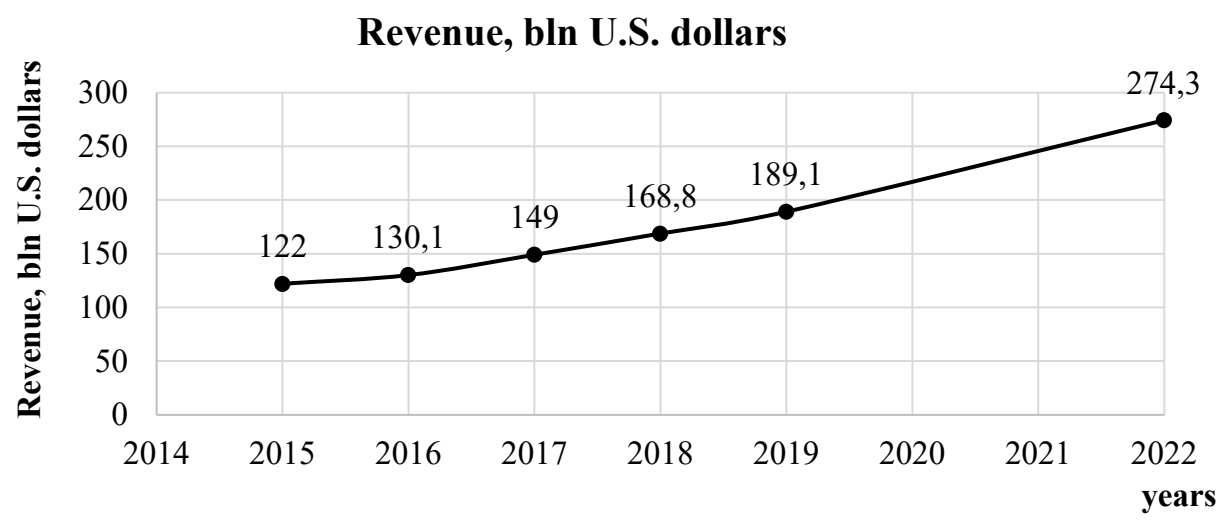

Figure 1. Revenue from big data and business analytics worldwide from 2015 to 2022 (2019-2022 - forecast)

Source: Statista

Features of digital innovations. In general, the DE opened up a large new area for innovations and gave impetus to the innovative entrepreneurship activation. The term "digital innovations" began to be widely used in scientific literature, although the explanation of their essence and features is insufficient (such as innovations in the field of production in the J. Schumpeter's theory). Digital innovations include: computer technology, software, network equipment (including security), data storage and processing infrastructure (including cloud), solutions for data processing (analysis), parallel computing programs, collaboration platforms, web services, web portals, IoT infrastructure, mobile applications. Their main subject is transfer, processing and storage of data in digital form, therefore, innovations can be presented as a program code, mathematical methods and other algorithms, hardware devices. It should be noted that due to the fact that IT is integrated with "physical" technologies, the digital innovation sphere is very wide and deals with production equipment, transport, and energy. It is the software that is key to the technical functionality of the hardware. Therefore, software innovations give birth to innovations in all software intensive systems. Software can be considered as both an independent subject of innovation and a subject of innovation combined with technology. A part of digital innovations is related to the provision of new information services and the creation of information products (for example, data collections).

The result of digital innovations is new consumer value, speed and quality of information needs satisfaction, new data and the results of their analysis. Most digital innovations can be classified as global because they can be applied in almost all countries. They can be focused on business, public administration, science, industry and agriculture, the financial sector, and various social groups and individuals. Currently, a large number of innovations are in logistics, medicine, and education.
Compared to the "material" innovations (product and technological) that are characteristic of the industrial sphere, which J. Schumpeter wrote about, digital innovations have a number of important features, such as: "intangibility"; dynamism; continuity; uncertainty of consequences; "disruptive" character; special social orientation, taking into account psychological and behavioral aspects; proximity to human practices and communication (they complement and change the existing models); basing on data; accumulation, addition and change of human experience; predominance of empiricism and heuristics (lack of a scientific basis).

The diffusion of digital innovations has a special nature. In order to intensify these processes, in addition to level increase of professional training and attracting talent, it is necessary to: improve digital integration standards, including data infrastructures, and stimulate of innovative entrepreneurship linked to advanced science.

The role of diffusion of innovations in digital economy development. Innovation appears unevenly across time and space. Therefore, the prerequisite for the transition to $\mathrm{DE}$ is $\mathrm{DI}$, that is, the spread of new technologies from the places of their appearance to the places of use, and between economy sectors, between subjects, between or within social groups. DI is an objective phenomenon that is the main factor in overall technological progress. This is a social, infrastructural, and geographic process, on which the scale of the innovation adoption and technological base updating depends. As a result of DI, the number of users of new technologies increases; this is a prerequisite for $\mathrm{DE}$ formation.

DI is realized in a variety of ways, through different channels, including commercial (market) and noncommercial (non-market) channels. J. Schumpeter's views on the diffusion of innovations among manufacturers are generally known. However, in the field of IT, diffusion should also include the processes of technology promotion to the end users, since this 
forms the technology value. In this regard, the new IT imitation also takes place, which in fact is also the diffusion of new technological opportunities.

DI accompanies digital transformation processes and ultimately forms DE scope. Because of this, it can be considered as a "lever" that determines the impact of the $\mathrm{DE}$ on economic growth. Therefore, intensification of DI processes can be used as a way to build new growth models. It should also be noted that it is DI that is largely responsible for the structural changes and leads to the emergence of new industries. That is why it is a prerequisite for the creation of new jobs and, accordingly, overcoming the DE challenges concerned with the unemployment growth.

DI is critical for innovation stimulating through the development of certain innovations by all market participants. This corresponds to J. Schumpeter's theory, who considered DI as a process of cumulative increase in the number of subjects who own and use innovation. As innovation diffuses, competition stimulates new achievements. Therefore, DI is closely interwoven with innovative entrepreneurship and makes it possible to identify the leaders in generating innovations.

Summarizing the above, it should be noted that DI creates: 1) economies of scale, covering all sectors of the economy and social sphere; 2) chain effect, when changes (improvements) in some sectors cause changes in other functionally related industries; 3 ) cumulative effect, accumulating changes and leading to a further qualitative leap. The natural consequences of DI are increase in overall productivity, intensification, and changes in price levels in several related markets. This forms the advantages of $\mathrm{DE}$.

Due to the realizing of DI importance as a key driver for DE development, it is necessary to support all its forms that are: commercial and non-commercial technology transfer, marketing of new IT, oriented R\&D. Various mechanisms of cooperation in the field of technology transfer, namely consortia, associations, alliances are also important.

DI can be considered at the levels of the national economy, sectors, regions, enterprises, highlighting the factors corresponding to each level. The specific historical context of DI should be taken into account. Currently, DI leads to the emergence of a future long economic development cycle by providing DE formation.

\section{Practical recommendations}

Based on the results of this study, a number of conceptual recommendations for DI processes intensifying can be proposed in the context of constructing DE. Firstly, the most important prerequisite for ensuring a dynamic DI is targeted government support that, among other things, should have regulatory functions. In addition to assistance in the development and implementation of innovative projects, such support can be aimed at providing DI, including a wide range of innovation policy methods (targeted grant financing, creation of innovative infrastructure, tax and credit benefits, educational support, etc.), including transfer and development of new technologies, as well as business adaptation to DE. This is the case not only of the IT sector, but also of other economy sectors that stimulate the new technologies demand. In the field of government support, it is also proposed to form special regulatory regimes, especially for small and medium-sized businesses (as technology recipients) and universities (as technology suppliers).

Secondly, in order to provide the organizational basis for DI, it is necessary to create special institutions (centers of transfer and commercialization of technologies, etc.), technological platforms and programs (of technological leadership and experience exchange) that are focused on IT diffusion. Such structures can be initiated at the national and regional levels in the context of DE development strategy. Cluster policy, industrial integration models, expert networks, professional communities, and centers of collective use can be supporting. From an organizational point of view, it is necessary to create new models of targeted network partnerships. It is also advisable to create a national network of laboratories for the development and adoption of new technologies, including those that deal with the same technologies in different locations.

Thirdly, in view of the need to ensure a balanced technological and social (human) development, education and training that create the necessary (for certain specialists and the general population) level of IT skills are of key importance. Therefore, it is advisable to expand the role of universities, focusing their educational activities on ensuring the DI processes, for example, by special courses conducting in the framework of the large innovative projects implementation. This can be implemented on an interregional basis. In addition, universities can become the basis for the creation of the aforementioned infrastructure, technology platforms and implementation of DI supporting programs.

Fourthly, it is necessary to support the functioning of research, innovations, entrepreneurial networks, professional communities, industry associations, expanding their role in DI processes. Such networks should become mechanisms of communication in the field of knowledge, practical adoption of technologies, training, etc. In this context, it is necessary to strengthen support for small and medium-sized innovative businesses, which should become a new technologies provider at the appropriate level.

Fifthly, using the advantages of the IT, it is advisable to create special-purpose software, such as: portals for management of oriented $R \& D$, experiments and adoption activities; knowledge management platforms in the context of technology transfer, and for the experience exchange; industry knowledge bases; portals 
for experts work activity management for project evaluation. Technology consulting and social research can complement this.

\section{Conclusion}

Thus, taking into account the essential features and structural changes caused by DE, orientation of innovation processes and, accordingly, the DI should be considered. Separately, it is necessary to associate DI with global technological trends and take into account the peculiarities of digital innovations as an object of spread. In this regard, the DI structure-forming role as a key driver for DE development that makes it possible to achieve a comprehensive scale of digital transformations, technological convergence and, as a result of the common digitalization benefits, has been substantiated. In order to intensify DI processes, a number of conceptual recommendations has been proposed in the context of DE building, including: implementation of targeted government support; creation of special technological platforms, a national network of technological laboratories; and conducting leadership and experience exchange programs, training courses for specialists to adopt innovations; creation of knowledge bases, etc. Prospective studies are expected to focus on detailing of these recommendations.

\section{References:}

Choi, S. Y., \& Whinston, A. B. (2000). The Internet Economy: Technology and Practice. SmartEcon Publishing.

Brynjolfsson, E., \& Kahin, B. (2000). Understanding the Digital Economy: Data, Tools, and Research. Cambridge: MIT Press.

Hevner, A., \& Gregor, Sh. (2020). Envisioning entrepreneurship and digital innovation through a design science research lens: A matrix approach. Information \& Management, Article 103350. doi: 10.1016/j.im. 2020.103350 .

Iden, J., Eikebrokk, T. R., \& Marrone, M. (2020). Process reference frameworks as institutional arrangements for digital service innovation. International Journal of Information Management, 54, Article 102150. doi: 10.1016/ j.ijinfomgt.2020.102150

Teece, D. J. (2018). Profiting from innovation in the digital economy: Enabling technologies, standards, and licensing models in the wireless world. Research Policy, 47(8), 1367-1387. doi: 10.1016/j.respol.2017.01.015

El-Haddadeh, R. (2020). Digital Innovation Dynamics Influence on Organisational Adoption: The Case of Cloud Computing Services. Information Systems Frontiers, 22(4), 985-999.

Räisänen, J., \& Tuovinen, T. (2020). Digital innovations in rural micro-enterprises. Journal of Rural Studies, 73, 56-67. doi: 10.1016/j.jrurstud.2019.09.010

Lai, P. C. (2017). The Literature Review of Technology Adoption Models and Theories for the Novelty Technology. Journal of Information Systems and Technology Management, 14(1), 21-38.

Taherdoost, H. (2018) A review of technology acceptance and adoption models and theories. Procedia Manufacturing, 22, 960-967.

Benson, T. (2019). Digital innovation evaluation: user perceptions of innovation readiness, digital confidence, innovation adoption, user experience and behaviour change. BMJ Health \& Care Informatics, 26. doi: 10.1136/ bmjhci-2019-000018

Talwar, Sh., Talwar, M., Kaur, P., \& Dhir, A. (2020). Consumers' resistance to digital innovations: A systematic review and framework development. Australasian Marketing Journal (AMJ), 28(4), 286-299. doi: 10.1016/ j.ausmj.2020.06.014

Jahanmir, S. F., \& Cavadas, J. (2018). Factors affecting late adoption of digital innovations. Journal of Business Research, 88, 337-343. doi: 10.1016/j.jbusres.2018.01.058

Park, H. J., \& Choi, S. O. (2019). Digital Innovation Adoption and Its Economic Impact Focused on Path Analysis at National Level. Journal of Open Innovation: Technology, Market, and Complexity, 5(3), Article 56. doi: 10.3390/ joitmc5030056

Bilozubenko, V., Yatchuk, O., Serediuk, T., \& Korneyev, M. (2020). Comparison of the digital economy development parameters in the EU countries in the context of bridging the digital divide. Problems and Perspectives in Management, 18(2), 206-218. doi: 10.21511/ppm.18(2).2020.18

Park, H. S. (2017). Technology convergence, open innovation, and dynamic economy. Journal of Open Innovation: Technology, Market, and Complexity, 3, Article 24. Available at: https://jopeninnovation.springeropen.com/track/pdf doi: 10.1186/s40852-017-0074-z

Mubarak, M. F., \& Petraite, M. (2020). Industry 4.0 technologies, digital trust and technological orientation: What matters in open innovation? Technological Forecasting and Social Change, 161, Article 120332. doi: 10.1016/ j.techfore.2020.120332

Pereira, A., \& Romero, F. (2017). A review of the meanings and the implications of the Industry 4.0 concept. Procedia Manufacturing, 13, 1206-1214. doi: 10.1016/j.promfg.2017.09.032

Njoh, A. J. (2018). The relationship between modern Information and Communications Technologies (ICTs) and development in Africa. Utilities Policy, 50, 83-90. 
Myovella, G., Karacuka, M., \& Haucap, J. (2020). Digitalization and economic growth: A comparative analysis of Sub-Saharan Africa and OECD economies. Telecommunications Policy, 44(2), Article 101856. doi: 10.1016/ j.telpol.2019.101856

Larson, J. F. (2017). Network-centric digital development in Korea: Origins, growth and prospects. Telecommunications Policy, 41(10), 916-930. doi: 10.1016/j.telpol.2017.03.007

Nambisan, S., Wright, M., \& Feldman, M. (2019). The digital transformation of innovation and entrepreneurship: Progress, challenges and key themes. Research Policy, 48(8), 1-9. doi: 10.1016/j.respol.2019.03.018

Zutshi, A., \& Grilo, A. (2019). The Emergence of Digital Platforms: A Conceptual Platform Architecture and impact on Industrial Engineering. Computers \& Industrial Engineering, 136, 546-555. doi: 10.1016/j.cie.2019.07.027

Chae, B. (2019). A General framework for studying the evolution of the digital innovation ecosystem: The case of big data. International Journal of Information Management, 45, 83-94. doi: 10.1016/j.ijinfomgt.2018.10.023

Abuladze, R., \& Gigauri, I. (2017). Ecosystem of Digital Economy in Georgia. SSRN Electronic Journal. doi: $10.2139 /$ ssrn.2958038

Linkov, I., Trump, B., Poinsatte-Jones, K., \& Florin, M.-V. (2018). Governance Strategies for a Sustainable Digital World. Sustainability, 10(2), Article 440. doi: 10.3390/su10020440

Bukht, R., \& Heeks, R. (2018). Digital Economy Policy in Developing Countries. DIODE Working Paper no. 6 Centre for Development Informatics Global Development Institute, SEED. doi: 10.13140/RG.2.2.24272.15364

Foster, C., \& Azmeh, Sh. (2019). Latecomer Economies and National Digital Policy: An Industrial Policy Perspective. The Journal of Development Studies, 56(7), 1247-1262. doi: 10.1080/00220388.2019.1677886

Hanna, N. (2018). A role for the state in the digital age. Journal of Innovation and Entrepreneurship, 7 , Article 5(2018). doi: 10.1186/s13731-018-0086-3

Amuso, V., Poletti, G., \& Montibello, D. (2019). The Digital Economy: Opportunities and Challenges. Global Policy, 11(1), 124-127. doi: 10.1111/1758-5899.12745

Lei, M. (2016). Determinants of IT Innovation Diffusion from Dynamic Perspective - Review and Prospects. Technology and Investment, 7, 1-7. doi: 10.4236/ti.2016.71001

Pradhan, R. P., Arvin, M. B., Nair, M., Bennett, S. E., \& Hall, J. H. (2019). The information revolution, innovation diffusion and economic growth: an examination of causal links in European countries. Quality \& Quantity, 53(3), 1529-1563.

Ali, M., \& Mahdi, H. M. (2016). The Cultural Impact of Diffusion of IT Innovation in World Society. International Conference on Recent Advances in Computer Systems (RACS 2015), Saudi Arabia. Atlantis Press, 114-118. doi: $10.2991 /$ racs-15.2016.19

Cisco Annual Internet Report (2018-2023). White Paper (2020). Cisco public. Available at: https://www.cisco.com/c/en/us/solutions/collateral/executive-perspectives/annual-internet-report/whitepaper-c11-741490.pdf 